\title{
Atorvastatin inhibits the expression of RAGE induced by advanced glycation end products on aortas in healthy Sprague-Dawley rats
}

Lei Xu1, Panpan Zang ${ }^{2}$, Bo Feng ${ }^{1 *}$ and Qiaohui Qian ${ }^{3}$

\begin{abstract}
Background: Atorvastatin can downregulate the expression of receptor for advanced glycation end products (RAGE) in the aortas of diabetic rats. However, its effect on healthy rats remains unclear. The aim of this study was to observe the direct impact of atorvastatin on advanced glycation end products- (AGEs) induced RAGE expression in healthy Sprague Dawley (SD) rats.
\end{abstract}

Methods: SD rats received AGE-BSA (20 mg/kg/day or $40 \mathrm{mg} / \mathrm{kg} /$ day), dual treatment (AGE-BSA $40 \mathrm{mg} / \mathrm{kg} /$ day and atorvastatin $20 \mathrm{mg} / \mathrm{kg} /$ day) or no treatment for 12 and 24 weeks, respectively. The deposition of AGEs and expression of RAGE in the animals' aortas were assessed by Quantitative RT-PCR, immunohistochemistry, and western-blot tests. Serum levels of AGEs were measured using ELISA.

Results: AGE-BSA upregulated the serum level of AGEs, deposition of AGEs, and expression of RAGE in aortas in a time- and dose-dependent way that can accelerate the development and progression of atherosclerosis. These upregulations could be significantly attenuated by atorvastatin in the absence of its lipid-lowering effects. These data provide further evidence for the novo mechanism of atorvastatin's pleiotropic effect.

Conclusion: Atorvastatin has a direct inhibitory effect on AGEs-RAGE expression in healthy SD rats. These potential pleiotropic vasculoprotective effects are independent of effects on glucose and lipid control.

Keywords: AGEs, RAGE, Atorvastatin, Atherosclerosis

\section{Background}

Hyperglycaemia drives non-enzymatic glycation and oxidation of proteins and lipids, which enhances irreversible formation of advanced glycation end products (AGEs) [1]. Accumulation of preformed AGEs in the vessel wall has been shown to promote diabetic vascular diseases [2]. The receptor for AGEs (RAGE) is a multi-ligand receptor that mediates the action of AGEs.

RAGE was initially isolated from the lung, but is also expressed on the surface of vascular endothelial cells, smooth muscle cells, and macrophages [3]. Accumulating evidence suggests that RAGE plays a pivotal role in promoting inflammatory processes and endothelial activation, which accelerates atherosclerosis in patients with

\footnotetext{
* Correspondence: bfeng2010@hotmail.com

${ }^{1}$ Department of Endocriology and Metabolic Disease, East Hospital, Tongji

University School of Medicine, Shanghai 200120, China

Full list of author information is available at the end of the article
}

diabetes [4]. Binding of AGEs to RAGE activates multiple intracellular signalling pathways, including p21ras, which recruits downstream targets such as mitogen-activated protein kinases (MAPK) and activates nuclear factor kap$\mathrm{paB}(\mathrm{NF}-\mathrm{kB})[5,6]$. The AGEs-RAGE interaction augments inflammatory responses and leads to vascular dysfunction and monocyte activation [7]. Diabetes-associated atherosclerotic lesions display increased accumulation of RAGE ligands and enhanced expression of RAGE $[4,8]$.

3-Hydroxy-3-methylglutaryl CoA (HMG-CoA) reductase inhibitors, also known as statins, are commonly used for the treatment of dyslipidaemia. A large number of studies have demonstrated that statin therapy is associated with a reduction in cardiovascular events in people both with and without diabetes [9-12]. While a reduction in low-density lipoprotein- cholesterol (LDL-C) was observed in many of these studies, it is now considered that statins also mediate pleiotropic antiatherogenic effects that are 
partially independent of their cholesterol-lowering effects and may contribute to their efficacy in reducing cardiovascular events. These cholesterol-independent effects include improving endothelial function, attenuating vascular and myocardial remodelling, inhibiting vascular inflammation and oxidation, and stabilizing atherosclerotic plaques [13-15].

In our previous study, we found that atorvastatin can significantly downregulate the expression of RAGE in aorta of diabetic Goto Kakisaki (GK) rats [16]. Those data demonstrated a novel "pleiotropic" activity of atorvastatin in reducing the risk of cardiovascular diseases by targeting RAGE expression. However, no work has been done on the direct effects of atorvastatin on the formation and deposition of AGEs and the expression of RAGE in healthy animal models. In the present study, we provided novel data that suggested atorvastatin could decrease the AGEs-induced increase in serum level of AGEs and suppress the expression of RAGE of aorta in Sprague Dawley (SD) rat models in euglycemic conditions. These results will further confirm the pleiotropic activity of atorvastatin by targeting RAGE.

\section{Methods}

\section{Preparation of AGEs}

Bovine serum albumin (BSA) and D-glucose were dissolved in PBS ( $\mathrm{pH} 7.2-7.4)$ : the final concentrations of $\mathrm{BSA}$ and D-glucose were $5 \mathrm{~g} / \mathrm{L}$ and $50 \mathrm{mmol} / \mathrm{L}$, respectively. EDTA was added to a final concentration of $0.5 \mathrm{mmol} / \mathrm{L}$ to reduce oxidation. Penicillin $(100 \mathrm{U} / \mathrm{L})$ and streptomycin $(100 \mu \mathrm{g} / \mathrm{ml})$ were added to the reaction mixture to prevent bacterial contamination. The reaction mixture was filtered through $0.22 \mu \mathrm{m}$ filter and then incubated at $37^{\circ} \mathrm{C}$ for 12 weeks.

At the end of the incubation period, the reaction mixture was dialyzed against sterilized PBS ( $\mathrm{pH} 7.2-7.4)$ to remove the unconjugated glucose. The glucose level in the dialyzate was $<0.03 \mathrm{mmol} / \mathrm{L}$. The reaction mixture was measured in a fluorospectrophotometer with an excitation wave of $370 \mathrm{~nm}$, and the maximum absorption peak was measured at $440 \mathrm{~nm}$ to verify that the mixture was glycated-BSA. Finally, the glycated-BSA was freezedried and stored at $4^{\circ} \mathrm{C}$.

\section{Animal experiment and sample collection}

Male SD rats (SLRC Laboratory Animal centre, Shanghai, China) weighing 200-250 g (starting age 8 weeks) were divided into five groups. Group A ate standard chow $(\mathrm{n}=10)$. Group B had a high-fat diet containing $69.13 \%$ standard chow to which we added $1.37 \%$ cholesterol, $0.5 \%$ bile salts, 9\% sugar, and 20\% lard. $(n=10)$. Group $\mathrm{C}$ ate the high-fat diet plus AGEs with glycatedBSA $20 \mathrm{mg} / \mathrm{kg}$ body weight per day through intraperitoneal injection $(n=10)$. Group $D$ ate the high-fat diet plus AGEs with glycated-BSA $40 \mathrm{mg} / \mathrm{kg}$ body weight per day through intraperitoneal injection $(n=10)$. Group E consumed the high-fat diet plus AGEs with glycatedBSA $40 \mathrm{mg} / \mathrm{kg}$ body weight per day through intraperitoneal injection and atorvastatin (Lipitor, Pfizer Ireland Pharmaceuticals) $20 \mathrm{mg} / \mathrm{kg} /$ day, through intragastric administration $(\mathrm{n}=10)$.

We chose SD rats as the animal models because of their normal glucose levels without obvious insulin resistance compared with the Goto Kakisaki (GK) rats used in our previous study. We chose the dose of atorvastatin mainly on the basis of our previous study [16]. As one of a series of experiments, we chose the same dose of atorvastatin for comparisons. It is higher than the human dose $(1.1 \mathrm{mg} / \mathrm{kg}$ per day) recommended for treatment of hypercholesterolemia [17], but consistent with the pharmacokinetic data indicating a higher metabolic rate of the drug in rodents [18].

Body weight was measured weekly. At the end of the 12 th and the 24th week, five rats per group were anaesthetised by an intraperitoneal injection of pentobarbitone sodium (100 mg/kg body weight) (Euthatal; Sigma-Aldrich, Castle Hill, NSW, Australia). Blood was collected from the left ventricle and centrifuged $(6,000 \times \mathrm{g})$, and plasma samples were stored at $-20^{\circ} \mathrm{C}$ for subsequent analysis. Animals were sacrificed and the aortas were rapidly dissected and snap frozen in liquid nitrogen and stored at $-80^{\circ} \mathrm{C}$ or stored in buffered formalin (10\%, vol./vol.) for subsequent measurement. All animal experiments were conducted according to the protocol approved by the Animal Committee of the Animal Center of East Hospital, Tongji University.

\section{Measurement of serum glucose, lipids, and AGEs}

Serum glucose levels were measured by the glucose oxidase method (Sigma, MO). Total cholesterol, triglycerides, LDL-C and high-density lipoprotein-cholesterol (HDL-C) levels were measured using a kit from Sigma Diagnostics. The serum levels of AGEs were determined using commercially available enzyme linked immunosorbent assay (ELISA) kits (Xitang Bio Technology Co, Shanghai, China) according to the manufacturer's instructions.

\section{Quantitative real-time PCR analysis}

Total RNA was isolated with the trizol method and depurated with an RNAeasy kit (Invitrogen, CA). RNA was stored at $-80^{\circ} \mathrm{C}$ until reverse transcription was performed. An aliquot $(1 \mu \mathrm{g})$ of extracted RNA was reverse-transcribed into the first strand of complementary DNA (cDNA) at $42^{\circ} \mathrm{C}$ for $40 \mathrm{~min}$, using $100 \mathrm{U} / \mathrm{ml}$ reverse -transcriptase (Takara Biochemicals, Shiga, Japan) and $0.1 \mu \mathrm{M}$ of oligo (dt)- adapter primer (Takara) in a $50 \mathrm{ul}$ reaction mixture. 
Real-time polymerase chain reaction (PCR) was carried out with an ABI Prism 7000 Real-Time PCR system, using the DNA-binding dye SYBER Green I for the detection of PCR products. The reaction mixture (RT-PCR kit, Takara) contained $12.5 \mu \mathrm{l}$ Premix Ex Tag, $2.5 \mu \mathrm{l}$ SYBER Green I, custom-synthesized primers, ROX reference dye, cDNA (equivalent to $20 \mathrm{ng}$ total RNA) to give a final reaction volume of $25 \mu \mathrm{l}$. Primers were as follows:

\section{GAPDH: sense 5’AGAGGAGAGGAAGGCCCCAGA} 3', antisense 5'GGCAAGGTGGGGTTATACAGG 3';

\section{RAGE: sense 5'GACAACTTTGGCATCGTGGA 3', antisense 5'ATGCAGGGATGATGTTCTGG 3'.}

The PCR settings were as follows: initial denaturation of $30 \mathrm{~s}$ at $95^{\circ} \mathrm{C}$, followed by 40 cycles of amplification for $5 \mathrm{~s}$ at $95^{\circ} \mathrm{C}$ and $34 \mathrm{~s}$ at $60^{\circ} \mathrm{C}$, with subsequent melting curve analysis increasing the temperature from $60^{\circ} \mathrm{C}$ to $95^{\circ} \mathrm{C}$. To quantify RAGE gene expression, the RAGE mRNA level was normalized by internal GADPH mRNA.

\section{Hematoxylin and eosin (HE) staining and immunohistochemistry}

Thoracic aorta sections were rehydrated and placed in Gill's c2 hematoxylin (Medical reagent company, Shanghai, China) and then transferred to an eosin Y solution (Medical reagent company, Shanghai, China). After staining, the sections were dehydrated through the alcohol series back to xylene and a coverslip was mounted to each slide with Permount.

Immunostaining of AGEs and RAGE was performed using the Vectastain Elite ABC Mouse/Rabbit IgG kit based on an avidin/biotin/peroxidase system (Boster Biotechnology Co. Ltd, Wuhan, China) according to the manufacturer's instructions. Briefly, the sections were incubated with $5 \%$ bovine serum albumin in PBS at room temperature for $30 \mathrm{~min}$ to block nonspecific binding of the second antibody and then reacted with the primary antibodies against AGEs (1:50, Santa Cruz Biotechnology) or RAGE (1:50, Santa Cruz Biotechnology) at $4^{\circ} \mathrm{C}$ overnight. Then they were exposed to the biotinylated secondary antibody at room temperature for $30 \mathrm{~min}$. After washing in PBS, the specimens were incubated with an avidin-biotin-peroxidase complex at room temperature for $30 \mathrm{~min}$. Deposition was visualized by treating the sections with DAB. The sections were viewed and photographed with an Olympus XI 70 microscope and digital imaging system (Olympus Optical, Tokyo, Japan). Image Pro Plus 6.0 was used to analyse the average of optical density (AOD) in the positive staining area.

\section{Western blot analysis}

Aortas were dissected and used to analyse protein levels by western blot. The lysates $(30 \mu \mathrm{g}$ protein) were separated by $10 \%$ SDS-PAGE, transferred to a PVDF membrane (Millipore), blocked with 5\% non-fat dry milk for $60 \mathrm{~min}$, and probed overnight with antibodies at $4^{\circ} \mathrm{C}$. The blots were incubated with HRP-conjugated anti-IgG for $1 \mathrm{~h}$ at $37^{\circ} \mathrm{C}$. We detected protein bands using chemiluminescence reagent Amersham ECL plus (GE Healthcare, Buckinghamshire, UK). Relative intensities of protein bands were analysed by Gel-Pro Analyzer software. Antibodies against RAGE (1:1000 dilution) and $\beta$-actin (1:1000 dilution) were purchased from Cell Signaling, USA.

\section{Statistical analysis}

All data were expressed as mean \pm SD. Kruskal-Wallis one-way analysis of variance was used to assess the differences between groups using SPSS 13.0 software. We considered values of $\mathrm{P}<0.05$ statistically significant.

\section{Results}

Metabolic parameters

At the end of the 12th week, the body weights of rats in Groups C and D were higher as compared to other groups, but that changes were statistically insignificant. But at the end of the 24th week, a significant increase in body weight in Group D was observed $(P<0.05)$. Serum glucose levels and LDL-C levels were not different among all five groups at both the 12th week and the 24th week (Table 1).

\section{The change of serum AGEs levels}

Compared with Group A, there was significant increase (about double) in the serum AGEs levels in Group B at the 12 th and the 24 th weeks $(52.85 \pm 3.08$ vs $25.78 \pm 4.09$ at the 12 th week,49.91 \pm 4.70 vs $21.69 \pm 3.88$ at the 24th week, $P<0.05)$. AGEs-BSA treatment induced a further increase compared with Group B, and at the 24th week, the high-dose AGEs-BSA treated group (Group D) had the highest level of all groups with statistical significance, compared to Group A (about 3.3 times as much) $(72.02 \pm 4.37$ vs $21.69 \pm 3.88, P=0.002)$ and Group B (about 1.4 times) $(72.02 \pm 4.37$ vs $49.91 \pm 4.70, P=0.009)$. Atorvastatin treatment reduced the serum AGEs level (Group E) compared with group D by a $26 \%$ change with statistical significance at the 24th week $(53.43 \pm 3.05$ vs $72.02 \pm 4.37, P=0.013)$. AGEs levels in Group E were not significantly different compared with Group B, but still higher than Group A about double $(53.43 \pm 3.05$ vs $21.69 \pm 3.88, P=0.006$ ) (Figure 1 ).

\section{Accumulation of AGEs in aortic wall}

The presence of AGEs in aortic walls was immunohistochemically examined in the tissue specimens of the aortas from the five experimental groups. There was no obvious positive immunostaining of AGEs in each group at the 12th week (Figure 2 A1-E1). At the 24th week, 
Table 1 Metabolic parameters of SD rats in different groups

\begin{tabular}{|c|c|c|c|c|c|c|}
\hline & \multicolumn{2}{|l|}{ Body weight } & \multicolumn{2}{|c|}{ Serum glucose } & \multicolumn{2}{|l|}{ LDL-C } \\
\hline & 12th week & 24th week & 12th week & 24th week & 12th week & 24th week \\
\hline Group A & $603.40 \pm 37.72$ & $750.20 \pm 40.24$ & $5.62 \pm 0.28$ & $6.29 \pm 0.24$ & $2.78 \pm 0.62$ & $1.81 \pm 0.38$ \\
\hline Group B & $621.25 \pm 46.82$ & $720.36 \pm 33.69$ & $6.18 \pm 0.67$ & $5.79 \pm 0.66$ & $1.74 \pm 0.58$ & $1.79 \pm 0.52$ \\
\hline Group C & $630.13 \pm 28.41$ & $784.35 \pm 38.53$ & $5.98 \pm 1.16$ & $5.72 \pm 0.69$ & $2.08 \pm 0.37$ & $2.24 \pm 0.42$ \\
\hline Group D & $626.38 \pm 32.32$ & $806.61 \pm 48.25^{*}$ & $5.95 \pm 0.92$ & $6.24 \pm 0.75$ & $2.04 \pm 1.01$ & $2.08 \pm 0.85$ \\
\hline Group E & $616.13 \pm 42.38$ & $771.5 \pm 40.08$ & $5.62 \pm 0.90$ & $6.20 \pm 0.28$ & $2.74 \pm 0.29$ & $2.72 \pm 0.36$ \\
\hline
\end{tabular}

Group A: absolute controls, $(n=10)$; Group B: high fat diet $(n=10)$; Group C: high fat diet plus AGEs with glycated-BSA 20 mg/kg body weight ( $n=10)$; Group D: high fat diet plus AGEs with glycated-BSA $40 \mathrm{mg} / \mathrm{kg}(\mathrm{n}=10) \#$ Group E: high fat diet plus AGEs with glycated-BSA $40 \mathrm{mg} / \mathrm{kg}$ and atorvastatin. Each value represents the mean \pm S.D. ${ }^{*}=p<0.05$ vs. other groups at the end of 24 th week.

immunostaining of AGEs was obvious in Groups C and D (Figure 2 C2-D2), especially in Group D (Figure 2 D2). Atorvastatin attenuated AGEs accumulation significantly compared with Group D (Figure 2 E2).

Then the AOD in the positive staining area was analysed by software. At the 24th week, the accumulation of AGEs had a further increase in Group C and Group D (about double) with statistical significance, compared with Group A $(2.88 \pm 0.21$ vs $1.53 \pm 0.22,2.99 \pm 0.28$ vs $1.53 \pm 0.22$, respectively; $P<0.001$ ) and about 1.6 times that of Group B $(2.88 \pm 0.21$ vs $1.76 \pm 0.19 ; 2.99 \pm 0.28$ vs $1.76 \pm 0.19$, respectively; $P=0.001)$. Atorvastatin reduced the presence of AGEs without statistical significance compared with Group D at the 24th week (Figure 3).

\section{Expression of RAGE in mRNA levels in the aortic wall} Compared with Group A, the expression of RAGE mRNA was significantly increased in Groups B, C, and D at the

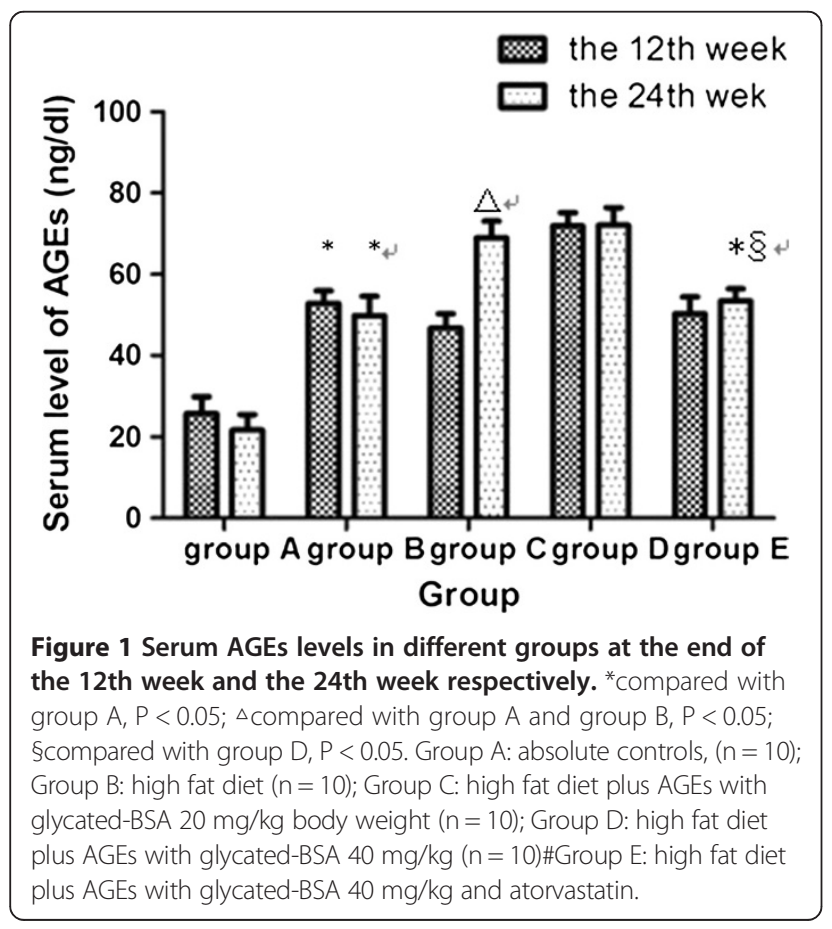

12th week $(P<0.01)$. At the 24 th week, RAGE mRNA level in Group D increased around 14 times compared with that in Group A and B $(187.16 \pm 16.33$ vs $13.08 \pm$ $2.34 ; 187.16 \pm 16.33 v s \quad 13.87 \pm 4.68$, respectively; $P<0.01)$ and about 3 times with that in Group C (187.16 \pm 16.33 vs $65.90 \pm 8.87 ; P=0.002)$. In the atorvastatin-treated group, however, RAGE mRNA levels were significantly downregulated to a level comparable to those observed in the normal Group A and high-fat diet Group B at the 24th week (Figure 4).

\section{Expression of RAGE in protein levels in the aortic wall}

Immunohistochemistry was used to observe expression of RAGE in aortas. Both at the 12th week and the 24th week, the expression of RAGE was higher in Group B than Group A. The AGEs-BSA treated groups (C and D) had higher expressions of RAGE than Group B. At the 24th week, deeper staining and more enlarged positive areas were observed in these five groups than at the 12th week. Atorvastatin reduced the expression of RAGE, compared with Group D (Figure 5).

The quantitative determination of RAGE in aorta was detected by western blot. There were no significant differences among five groups at the 12th week. At the 24th week, the expression of RAGE was significantly higher in Groups C and D than Group A $(13.04 \pm 2.17$ vs $1.07 \pm 0.02 ; P=0.023$ and $16.04 \pm 1.36$ vs $1.07 \pm 0.02 ; P=0.003$, respectively) and Group B $(13.04 \pm 2.17$ vs $4.92 \pm 1.98 ; P=0.032$ and $16.04 \pm$ 1.36 vs $4.92 \pm 1.98 ; P=0.008$, respectively). Atorvastatin significantly suppressed the expression of RAGE at the 24th week with about $66 \%$ decrease compared with Group D $(5.45 \pm 1.84$ vs $16.04 \pm 1.36, P=0.008)$ (Figure 6).

\section{Morphological examination of aortas}

The general morphology of aortas in all 5 groups at the 12 th week and the 24 th week remained relatively constant throughout the study.

\section{Discussion}

Statins may be able to reduce cardiovascular events by mechanisms other than their ability to lower the level of 


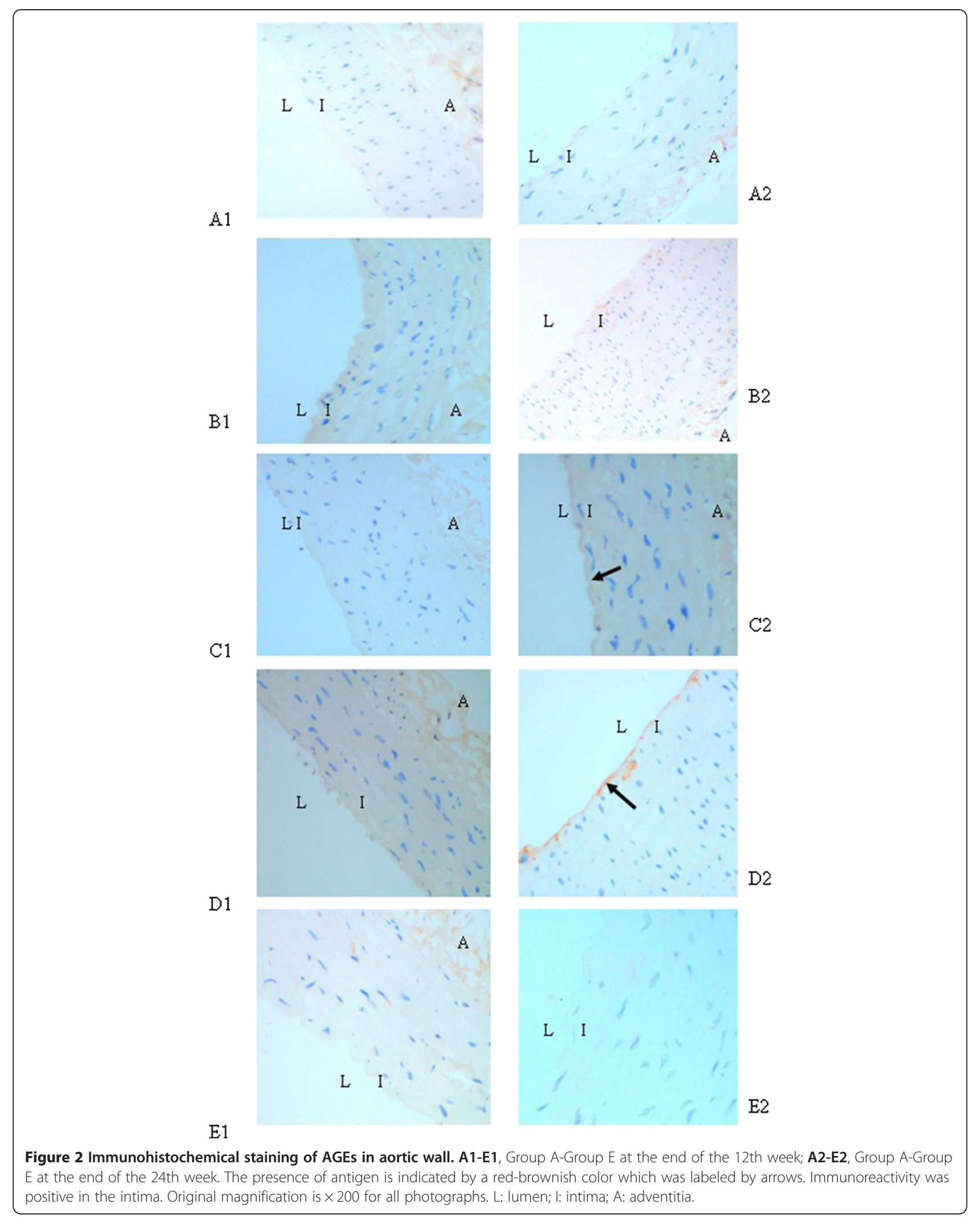




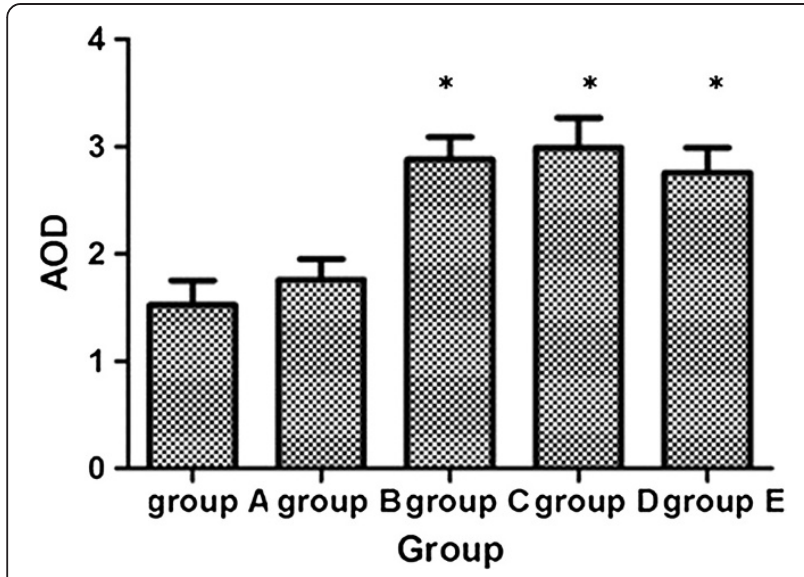

Figure 3 AOD of the positive staining area of AGEs in different groups at the end of the 24th week. * compared with group $A$ and group $B, P<0.05$.

serum lipids, i.e. the "pleiotropic" actions [19,20]. Furthermore, there is a growing body of evidence that statins can decrease the serum AGEs levels and expression of RAGE in diabetic aortas with atherosclerotic plaque [21-23]. This effect is supposed to be a novel molecular mechanism of statin's pleiotropic actions.

Previously we have demonstrated, using the diabetic GK rats, that the RAGE expression in diabetic rats was significantly reduced by treatment with atorvastatin independent of glycaemic and lipid control in the very early stage of atherosclerosis, possibly through an epigenetic mechanism [16]. However, nearly all prior studies have been done in diabetic animal models and cannot exclude the effects of interference factors such as the level of blood glucose on the results. Therefore these studies cannot provide exact evidence whether statins

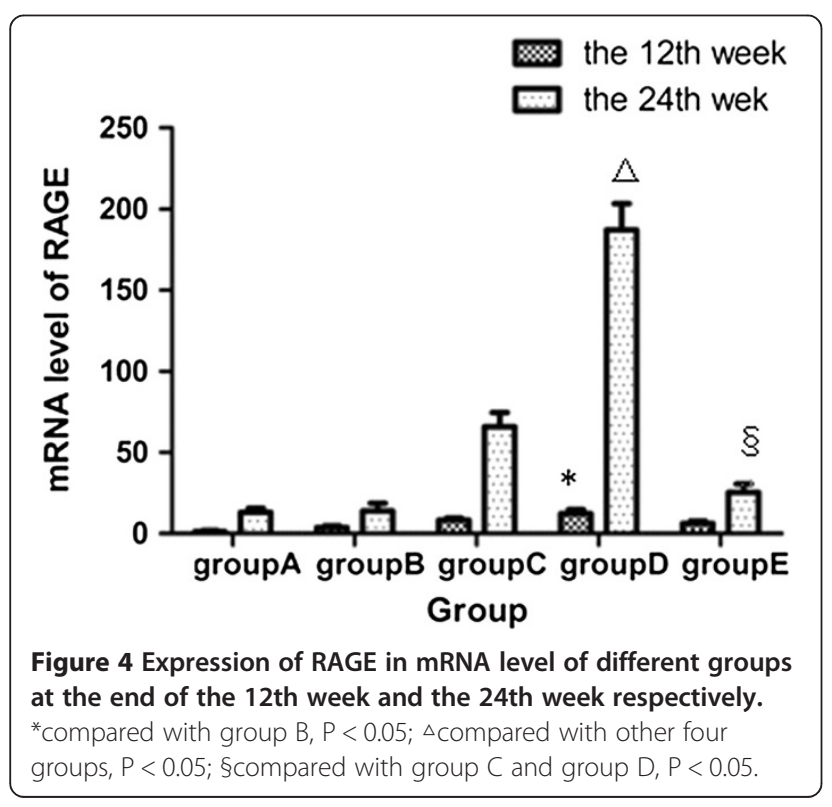

can inhibit the expression of RAGE directly in tissues of arteries. Therefore, in present study, we chose healthy $\mathrm{SD}$ rats treated with AGEs to simulate the diabetic pathological changes in arteries induced by AGEs to exclude the interference factors and to determine the direct effects of atorvastatin on regulation of AGEs and RAGE.

Although we divided the SD rats into a standard chow group and high fat diet groups and treated some of them by atorvastatin or AGEs, unexpectedly there were still no significant differences in glucose levels and lipid profile levels among these five groups. All the changes in this study were independent from glycaemic and lipid control.

In the present study, serum AGEs levels and the accumulation of AGEs in aortas were significantly increased by AGEs induction in a dose- and time-dependent manner. Concentrations of circulating AGEs correlate to the severity of coronary artery disease and adverse clinical outcomes [24]. Atorvastatin can reduce the serum level of AGEs in a time-dependent and a cholesterol-lowering independent manner; the exact mechanisms are unclear. Oxidative stress participates in the formation of AGEs, which are by themselves a source of free-radical superoxide generation as well $[25,26]$. Furthermore, hydroxyl metabolites of atorvastatin have been shown to have anti-oxidative properties [27].

Our previous study suggests that atorvastatin can improve the oxidative stress induced by AGEs. The present findings suggest that atorvastatin may decrease serum AGEs levels via its anti-oxidative property. On the other hand, atorvastatin may reduce the absorption of exogenous AGEs through peritoneal capillary networks and the intestinal canal through its anti-inflammatory and antioxidative properties, which can reduce the inflammatory action and oxidative stress of the intestinal wall [28,29]. This may be another possible mechanism to explain the effect of atorvastatin on decreasing serum AGEs levels.

In spite of the obvious reduction of serum AGEs level, we did not find a significant reduction of accumulation of AGEs in aorta in Group E, treated with atorvastatin, compared with Group D. AGEs slowly degrade and remain for a long time in diabetic vessels even after glycaemic control and oxidative stress conditions have improved [30]. Therefore, the phenomenon of so-called metabolic memory could be explained, in part, by AGEs [31]. In other words, the accumulation of AGEs on aortas may not be easily reversed by short-term statin therapy.

There is a growing body of evidence that RAGE may play a pro-atherogenic role in diabetic arteries [32,33]. Our data showed that the expression of RAGE on aortas significantly increased in AGEs-treated groups, and this increase correlated with time, course, and concentration 
A1

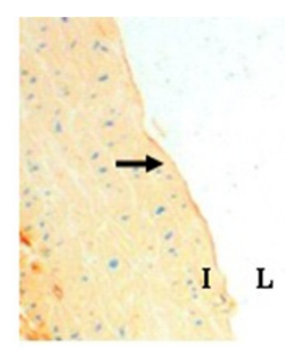

B1

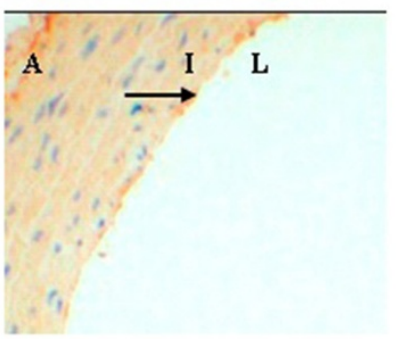

$\mathrm{C} 1$

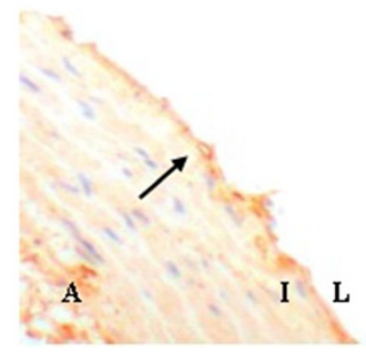

D1

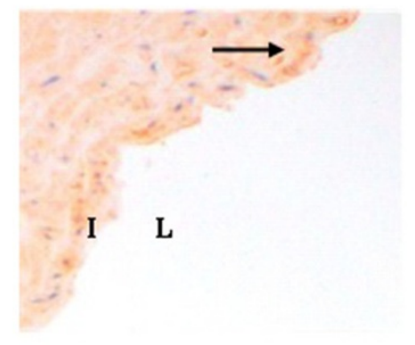

E1

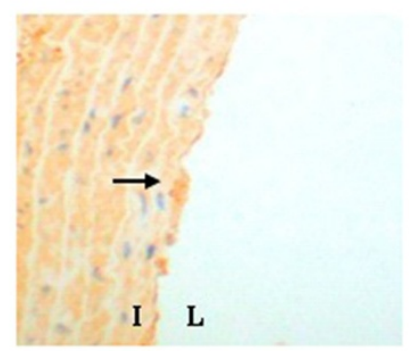

A2

L

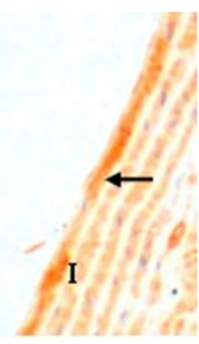

B2
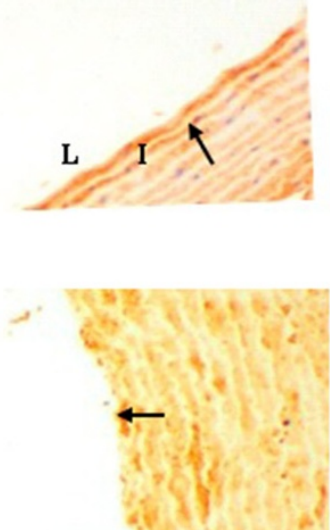

$\mathrm{C} 2$

L I
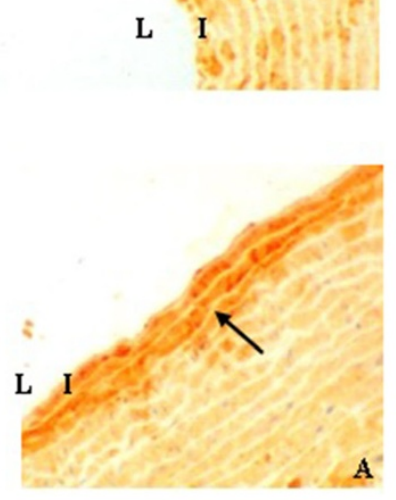

D2

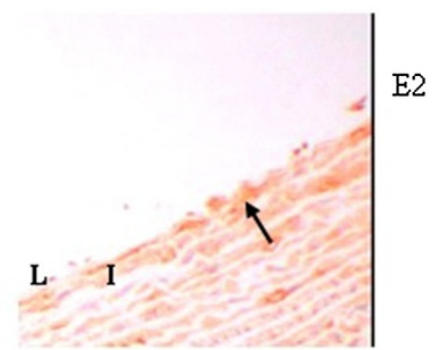

Figure 5 Expression of RAGE in aortic wall of different groups at the end of the $12^{\text {th }}$ week and the $24^{\text {th }}$ week by immunohistochemical staining. A1-E1, Group A-Group E at the end of the 12th week; A2-E2, Group A-Group E at the end of the 24th week. The presence of antigen is indicated by a red-brownish color which was labeled by arrows. Original magnification is $\times 200$ for all photographs. L: Iumen; I: intima; A: adventitia.

of serum AGEs. Atorvastatin could reduce the expression of RAGE on aortas both in the mRNA and protein levels, which is in line with our previous observations [16]. This effect of atorvastatin was partly independent of the reduction of AGEs accumulation on aortas.
Excluding other interference factors of hyperglycaemia in our present study, we can speculate that atorvastatin downregulated the expression of RAGE partly by reducing the serum AGEs levels and blocking the AGEsRAGE positive feedback loop. 


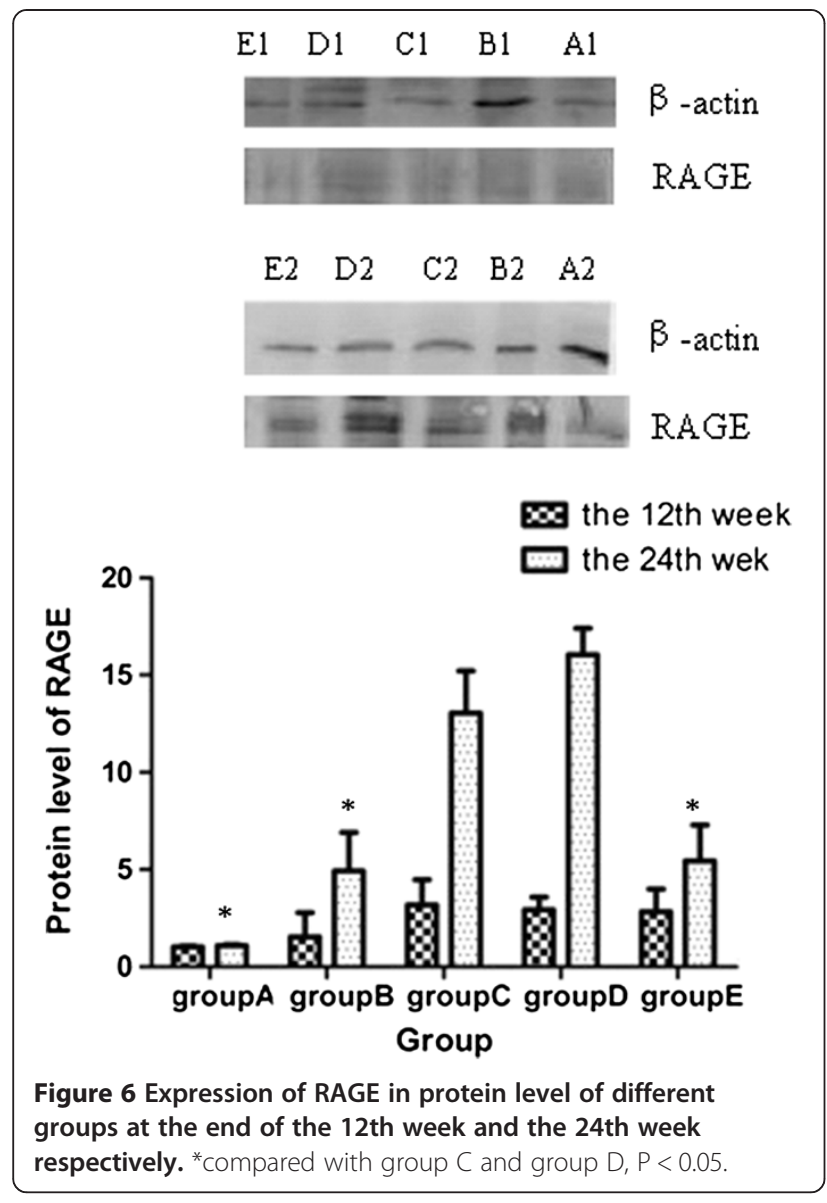

The other possible mechanism is that atorvastatin can inhibit gene expression of RAGE directly. There is a growing body of evidence that statins could inhibit plaque RAGE expression in type 2 diabetes [23,34,35]. Furthermore, our previous study demonstrated that atorvastatin suppressed the AGE/RAGE pathway by a gene targeting mechanism in diabetic atherosclerosis.

In the present study, we demonstrated that atorvastatin can downregulate RAGE expression in normal conditions without type 2 diabetes or atherosclerosis. These results are not only in accordance with our previous study, but also complement previous results. These data can provide further evidence for the novo mechanism of atorvastatin's pleiotropic effect.

Notably, the high-fat diet raised the serum level of AGEs and expression of RAGE in spite of a lack of change in the serum level of cholesterol. In our previous study, we found that a high-fat diet could promote the oxidative stress that may increase the formation of AGEs.

In addition, treatment of AGEs can increase the body weight of SD rats, although this has rarely been reported in previous studies, and the specific mechanism was unclear. One study found that weight increases were associated with skeletal muscle immunostaining for AGEs, RAGE, and oxidation injury [36]. The AGEsRAGE axis, oxidative stress, weight gain, and insulin resistance may correlate with each other, and further study should explore this area.

There was no change in the morphology of the aortas in the five groups, which was in accordance with our previous study [16]. This shows that atorvastatin can downregulate the AGEs-RAGE axis in the very early stages of atherosclerosis, before its therapeutic improvement of the atherosclerotic lesions can be detected histologically. Thus, our data demonstrate there would be more benefits for diabetic patients from using atorvastatin earlier at a full, effective dose.

\section{Conclusions}

The present results demonstrate the direct inhibitory effects of atorvastatin on AGEs-RAGE expression in healthy SD rats. These potential pleiotropic vasculoprotective effects are independent of effects on glucose and lipid control. This study provides strong evidence for the early use of atorvastatin in diabetes-associated atherosclerosis; this agent has the potential to exert superior long-term vasculoprotection. Future studies should be done to determine the exact molecular mechanisms and signalling pathways of the effects of atorvastatin on AGEs-RAGE expression.

\section{Abbreviations}

AGEs: Advanced glycation end products; RAGE: Receptor for advanced glycation end products; MAPK: Mitogen-activated protein kinases; NF-KB: Nuclear factor kappaB; HMG-CoA: 3-Hydroxy-3-methylglutaryl CoA; LDL-C: Low-density lipoprotein- cholesterol; GK: Goto Kakisaki; SD: Sprague Dawley; BSA: Bovin serum albumin; HDL-C: High density lipoprotein-cholesterol; ELISA: Enzyme linked immunosorbent assay; HE: Hematoxylin and eosin; AOD: Average of optical density.

\section{Competing interests}

The authors declare that they have no competing interests.

\section{Authors' contributions}

LX participated in the design of the study, carried out the

immunohistochemistry and drafted the manuscript. PZ carried out the animal experiment, RT-PCR, Western blot and performed the statistical analysis. BF conceived of the study, and participated in its design and coordination and helped to draft the manuscript. QQ participated in preparation of AGEs and Western blot. All authors read and approved the final manuscript.

\section{Acknowledgements}

This work was supported by the Basic Research Program of Shanghai (Granted No. 08JC1419900), the National Basic Research Program of China (973 Program) (Granted No. 2011CB504006), and the National Natural Science Foundation of China (Granted No. 81300699).

\section{Author details}

${ }^{1}$ Department of Endocriology and Metabolic Disease, East Hospital, Tongji University School of Medicine, Shanghai 200120, China. ${ }^{2}$ Department of Endocriology, Shanghai Ninth People's Hospital Affiliated Shanghai Jiaotong University School of Medicine, Shanghai 200120, China. ${ }^{3}$ Department of Endocriology, Shanghai Zhoupu Hospital, Shanghai 200120, China. 
Received: 18 February 2014 Accepted: 10 September 2014 Published: 23 September 2014

\section{References}

1. Ruderman NB, Williamson JR, Brownlee M: Glucose and diabetic vascular disease. FABEB J 1992, 6:2905-2914

2. Yan SF, Ramasamy R, Naka Y, Schmidt AM: Glycation, inflammation, and RAGE: a scaffold for the macrovascular complications of diabetes and beyond. Circ Res 2003, 93:1159-1169.

3. Brett J, Schmidt AM, Yan SD, Zou YS, Weidman E, Pinsky D, Nowygrod R, Neeper M, Przysiecki C, Shaw A, Migheli A, Stern D: Survey of the distribution of a newly characterized receptor for advanced glycation end products in tissues. Am J Pathol 1993, 143:1699-1712.

4. Cipollone F, lezzi A, Fazia M, Zucchelli M, Pini B, De Cuccurullo C, Cesare D, De Blasis G, Muraro R, Bei R, Chiarelli F, Schmidt AM, Cuccurullo F, Mezzetti A: The receptor RAGE as a progression factor amplifying arachidonatedependent inflammatory and proteolytic response in human atherosclerotic plaques: role of glycemic control. Circulation 2003, 108:1070-1077.

5. Huttunen HJ, Fages C, Rauvala H: Receptor for advanced glycation end products (RAGE)-mediated neurite outgrowth and activation of NFkappaB require the cytoplasmic domain of the receptor but different downstream signaling pathways. J Biol Chem 1999, 274:19919-19924.

6. Bierhaus A, Schiekofer S, Schwaninger M, Andrassy M, Humpert PM, Chen J, Hong M, Luther T, Henle T, Klöting I, Morcos M, Hofmann M, Tritschler H, Weigle B, Kasper M, Smith M, Perry G, Schmidt AM, Stern DM, Häring HU, Schleicher E, Nawroth PP: Diabetes-associated sustained activation of the transcription factor nuclear factor-kappaB. Diabetes 2001, 50:2792-2808.

7. Shanmugam N, Kim YS, Lanting L, Natarajan R: Regulation of cyclooxygenase-2 expression in monocytes by ligation of the receptor for advanced glycation end products. J Biol Chem 2003, 278:34834-34844.

8. Park L, Raman KG, Lee KJ, Lu Y, Ferran LJ Jr, Chow WS, Stern D, Schmidt AM: Suppression of accelerated diabetic atherosclerosis by the soluble receptor for advanced glycation endproducts. Nat Med 1998, 4:1025-1031.

9. Collins R, Armitage J, Parish S, Sleigh P, Peto R, Heart Protection Study Collaborative Group: MRC/BHF Heart Protection Study of cholesterollowering with simvastatin in 5963 people with diabetes: a randomised placebo-controlled trial. Lancet 2003, 361:2005-2016.

10. Sever PS, Dahlöf B, Poulter NR, Wedel H, Beevers G, Caulfield M, Collins R, Kjeldsen SE, Kristinsson A, Mclnnes GT, Mehlsen J, Nieminen M, O'Brien E, Ostergren J, ASCOT investigators: Prevention of coronary and stroke events with atorvastatin in hypertensive patients who have average or lower-than-average cholesterol concentrations, in the AngloScandinavian Cardiac Outcomes Trial-Lipid Lowering Arm (ASCOT-LLA): a multicentre randomised controlled trial. Lancet 2003, 361:1149-1158.

11. Keech A, Colquhoun D, Best J, Kirby A, Simes RJ, Hunt D, Hague W, Beller E, Arulchelvam M, Baker J, Tonkin A, LIPID Study Group: Secondary prevention of cardiovascular events with long-term pravastatin in patients with diabetes or impaired fasting glucose: results from the LIPID trial. Diabetes Care 2003, 26:2713-2721.

12. Colhoun HM, Betteridge DJ, Durrington PN, Hitman GA, Neil HA, Livingstone SJ, Thomason MJ, Mackness MI, Charlton-Menys V, Fuller JH, CARDS investigators: Primary prevention of cardiovascular disease with atorvastatin in type 2 diabetes in the Collaborative Atorvastatin Diabetes Study (CARDS): multicentre randomised placebo-controlled trial. Lancet 2004, 364:685-696.

13. Laufs U, La Fata V, Plutzky J, Liao JK: Upregulation of endothelial nitric oxide synthase by HMG CoA reductase inhibitors. Circulation 1998 , 97:1129-1135.

14. Li M, Liu Y, Dutt P, Fanburg BL, Toksoz D: Inhibition of serotonin-induced mitogenesis, migration, and ERK MAPK nuclear translocation in vascular smooth muscle cells by atorvastatin. Am J Physiol Lung Cell Mol Physiol 2007, 293:L463-L471

15. Scalia R, Gooszen ME, Jones SP, Hoffmeyer M, Rimmer DM 3rd, Trocha SD, Huang PL, Smith MB, Lefer AM, Lefer DJ: Simvastatin exerts both antiinflammatory and cardioprotective effects in apolipoprotein E-deficient mice. Circulation 2001, 103:2598-2603.

16. Feng B, Xu L, Wang H, Yan X, Xue J, Liu F, Hu JF: Atorvastatin exerts its anti-atherosclerotic effects by targeting the receptor for advanced glycation end products. Biochim Biophys Acta 2011, 1812:1130-1137.
17. Bernini F, Poli A, Paoletti R: Safety of HMG-CoA reductase inhibitors: focus on atorvastatin. Cardiovasc Drugs Ther 2001, 15:211-218.

18. Dostal LA, Whitfield LR, Anderson JA: Fertility and general reproduction studies in rats with the HMG-CoA reductase inhibitor, atorvastatin. Fundam Appl Toxicol 1996, 32:285-292.

19. Davignon J: Beneficial cardiovascular pleiotropic effects of statins. Circulation 2004, 109(23 Suppl 1):|l|139-|||43.

20. Ray KK, Cannon CP: The potential relevance of the multiple lipidindependent (pleiotropic) effects of statins in the management of acute coronary syndromes. J Am Coll Cardiol 2005, 46:1425-1433.

21. Okamoto T, Yamagishi S, Inagaki Y, Amano S, Koga K, Abe R, Takeuchi M, Ohno S, Yoshimura A, Makita Z: Angiogenesis induced by advanced glycation end products and its prevention by cerivastatin. FASEB J 2002, 16:1928-1930.

22. Calkin AC, Giunti C, Sheehy K, Chew C, Boolell V, Rajaram YS, Cooper ME, Jandeleit-Dahm KA: The HMG-CoA reductase inhibitor rosuvastatin and the angiotensin receptor antagonist candesartan attenuate atherosclerosis in an apolipoprotein E-deficient mouse model of diabetes via effects on advanced glycation,oxidative stress and inflammation. Diabetologia 2008, 51:1731-1740

23. Cuccurullo C, lezzi A, Fazia ML, De Cesare D, Di Francesco A, Muraro R, Bei R, Ucchino S, Spigonardo F, Chiarelli F, Schmidt AM, Cuccurullo F, Mezzetti A, Cipollone F: Suppression of RAGE as a basis of simvastatin-dependent plaque stabilization in type 2 diabetes. Arterioscler Thromb Vasc Biol 2006, 26:2716-2723.

24. Kilhovd BK, Juutilainen A, Lehto S, Rönnemaa T, Torjesen PA, Birkeland Kl, Berg TJ, Hanssen KF, Laakso M: High serum levels of advanced glycation end products predict increased coronary heart disease mortality in nondiabetic women but not in nondiabetic Men. A population-based 18-year follow-up study. Arterioscler Thromb Vasc Biol 2005, 25:815-820.

25. Yamagishi S, Imaizumi T: Diabetic vascular complications: pathophysiology, biochemical basis and potential therapeutic strategy. Curr Pharm 2005, 11:2279-2299.

26. Nishikawa T, Edelstein D, Du XL, Yamagishi S, Matsumura T, Kaneda Y, Yorek MA, Beebe D, Oates PJ, Hammes HP, Giardino I, Brownlee M: Normalizing mitochondrial superoxide production blocks three pathways of hyperglycaemic damage. Nature 2000, 404:787-790.

27. Aviram M, Rosenblat M, Bisgaier CL, Newton RS: Atorvastatin and gemfibrozil metabolites, but not the parent drugs, are potent antioxidants against lipoprotein oxidation. Atherosclerosis 1998, 138:271-280.

28. Kiener PA, Davis PM, Murray JL, Youssef S, Rankin BM, Kowala M: Stimulation of inflammatory responses in vitro and in vivo by lipophilic HMG-CoA reductase inhibitors. Int Immunopharmacol 2001, 1:105-118.

29. Stolf AM, Lívero Fdos R, Dreifuss AA, Bastos-Pereira AL, Fabosi IA, de Souza CE A, Gomes Lde O, Chicorski R, Brandt AP, Cadena SM, Telles JE, Hauser AB, Elferink RO, Zampronio AR, Acco A: Effects of statins on liver cell function and inflammation in septic rats. J Surg Res 2012, 178:888-897.

30. Yamagishi S: Role of advanced glycation end products (AGEs) and receptor for AGEs (RAGE) in vascular damage in diabetes. Exp Gerontol 2011, 46:217-224.

31. Nathan DM, Lachin J, Cleary P, Orchard T, Brillon DJ, Backlund JY, O'Leary DH, Genuth S, Diabetes Control and Complications Trial, Epidemiology of Diabetes Interventions and Complications Research Group: Diabetes control and complications trial, epidemiology of diabetes interventions and complications research group: intensive diabetes therapy and carotid intima-media thickness in type 1 diabetes mellitus. N Engl J Med 2003, 348:2294-2303.

32. Rahbar S, Figarola JL: Novel inhibitors of advanced glycation endproducts. Arch Biochem Biophys 2003, 419:63-79.

33. Bierhaus A, Hofmann MA, Ziegler R, Nawroth PP: AGE and their interaction with AGE-receptors in vascular disease and diabetes mellitus. I The AGE concept. Cardiovasc Res 1998, 37:586-600.

34. Cipollone F, Fazia M, lezzi A, Zucchelli M, Pini B, De Cesare D, Ucchino S, Spigonardo F, Bajocchi G, Bei R, Muraro R, Artese L, Piattelli A, Chiarelli F, Cuccurullo F, Mezzetti A: Suppression of the functionally coupled cyclooxygenase- 2/prostaglandin E synthase as a basis of simvastatindependent plaque stabilization in humans. Circulation 2003, 107:1479-1485.

35. Crisby M, Nordin-Fredriksson G, Shah PK, Yano J, Zhu J, Nilsson J: Pravastatin treatment increases collagen content and decreases lipid content, 
inflammation, metalloproteinases, and cell death in human carotid plaques: implications for plaque stabilization. Circulation 2001, 103:926-933.

36. de la Maza MP, Uribarri J, Olivares D, Hirsch S, Leiva L, Barrera G, Bunout D: Weight increase is associated with skeletal muscle immunostaining for advanced glycation end products, receptor for advanced glycation end products, and oxidation injury. Rejuvenation Res 2008, 11:1041-1048.

doi:10.1186/1758-5996-6-102

Cite this article as: Xu et al:: Atorvastatin inhibits the expression of

RAGE induced by advanced glycation end products on aortas in healthy

Sprague-Dawley rats. Diabetology \& Metabolic Syndrome 2014 6:102.

\section{Submit your next manuscript to BioMed Central and take full advantage of:}

- Convenient online submission

- Thorough peer review

- No space constraints or color figure charges

- Immediate publication on acceptance

- Inclusion in PubMed, CAS, Scopus and Google Scholar

- Research which is freely available for redistribution 